\title{
Characterization of hemocyanin from the mud crab Scylla paramamosain and its expression analysis in different tissues, at various stages, and under Vibrio parahaemolyticus infection
}

\author{
J. Wang ${ }^{1,2}$, F.Y. Zhang ${ }^{1}$, W. Song ${ }^{1}$, Y.B. Fang ${ }^{3}$, J.H. Hu ${ }^{1,2}$, M. Zhao ${ }^{1,2}$, K.J. Jiang ${ }^{1}$ \\ and L.B. Ma ${ }^{1}$ \\ ${ }^{1}$ East China Sea Fisheries Research Institute, Chinese Academy of Fishery Sciences, \\ Shanghai, China \\ ${ }^{2}$ College of Fisheries and Life Science, \\ Shanghai Ocean University, Shanghai, China \\ ${ }^{3}$ School of Life Sciences, Fudan University, Shanghai, China \\ Corresponding authors: K.J. Jiang / L.B. Ma \\ E-mail: jiangkj@ecsf.ac.cn / malingbo@vip.sina.com
}

Genet. Mol. Res. 14 (4): 16639-16651 (2015)

Received August 30, 2015

Accepted October 2, 2015

Published December 11, 2015

DOI http://dx.doi.org/10.4238/2015.December.11.11

\begin{abstract}
Hemocyanin is an important respiratory protein in many arthropod and mollusk species. Here, four cDNAs (SpHc1, SpHc2, $\mathrm{SpHc3}$, and SpHc4), encoding distinct hemocyanin subunits from Scylla paramamosain were cloned using EST analyses and the rapid amplification of cDNA ends. The four full-length cDNA fragments (SpHc1-4) were 2281, 2002, 2184, and $2069 \mathrm{bp}$, respectively, and they encoded four putative proteins (570-676 amino acids) with a molecular mass of $\sim 65.0-76.8 \mathrm{kDa}$. Quantitative real-time PCR analyses revealed that the four genes were mainly expressed in the hepatopancreas, testis, and hemocytes. $\mathrm{SpHc}$ mRNA expression during continuous developmental stages in zoeal phases
\end{abstract}


(Z1, Z2, Z3, Z4, and Z5), megalopa, and juvenile crab I stages were also detected. The expression levels of $\mathrm{SpHc} 3$ and $\mathrm{SpHc} 4$ were higher than that of $\mathrm{SpHc1}$ and $\mathrm{SpHc} 2$ during the first six stages, and they sharply declined during the juvenile stage. After infection with Vibrio parahaemolyticus, the temporal expression of both the four SpHc mRNAs in the megalopa stage rapidly declined during the first $3 \mathrm{~h}$, followed by upregulation and peak expression at $12 \mathrm{~h}$ after the challenge. The expression levels of the four $\mathrm{SpHc}$ subunits were upregulated at $48 \mathrm{~h}$ after the challenge, and were then gradually downregulated. These findings suggest that hemocyanin may potentially be involved in the crab immune response, and that the role of the four subunits may differ in different tissues and during various developmental stages.

Key words: Scylla paramamosain; Hemocyanin; Quantitative real-time PCR

\section{INTRODUCTION}

The mud crab (Scylla paramamosain) is one of the most precious marine crabs in aquaculture throughout the Indo-Pacific (Imjongjirak et al., 2007) and the Indian Ocean (Imai and Takeda, 2005). It possesses significant economic value, including use as a functional food. Mature female crabs are known as "sea ginseng," and they have become a favorite food of elderly people and pregnant women (Zhang et al., 2011). However, with the high stocking density associated with intensive culture and the deterioration of environmental conditions, mud crab deaths from bacterial, fungal, and viral diseases such as Vibrio parahaemolyticus (Sakazaki et al., 1963) have led to huge annual economic losses. An understanding of the innate immunity of $S$. paramamosain at the molecular level will help control disease in crab farming.

Since mud crabs are invertebrates that lack an acquired adaptive immune system, their host defense entirely depends on innate and non-adaptive mechanisms to resist pathogenic invasions (Zhang et al., 2013). The prophenoloxidase-activating system (proPO) is one of the most important non-self recognition systems in invertebrates (Gillespie and Kanost, 1997; Sritunyalucksana and Söderhäll, 2000; Lee and Söderhäll, 2002). Researchers found that this system consists of several different proteins, including zymogenic proteinases, proteinase inhibitors, proPO, and recognition molecules that distinguish pathogen-associated molecular patterns, including bacterial lipopolysaccharides or peptidoglycans and fungal $\beta-1,3-$ glucans (Lee et al., 2004). Hemocyanin is a multifunctional molecule that serves as an oxygen carrier for chelicerates, crustaceans, and other arthropods (Decker and Terwilliger, 2000). Recently, hemocyanin was reported to have phenoloxidase activity after proteolytic cleavage of the $\mathrm{N}$-terminal portion of hemocyanins in chelicerates (e.g., horseshoe crab, Tachypleus tridentatus) (Decker and Rimke, 1998). In addition, arthropod hemocyanins and phenoloxidases belong to a large protein superfamily that also includes copper-less, non-respiratory proteins such as decapod pseudo-hemocyanins (cryptocyanins), insect hexamerins, and hexamerin receptors (Burmester and Schellen, 1996; Burmester, 2001, 2002). In previous studies, researchers found that hemocyanin, like hemoglobin and many other proteins, is a multi-subunit molecule (Markl and Decker, 1992; Decker and Jaenicke, 2004). For example, the peacock mantis shrimp (Odontodactylus scyllarus) has four hemocyanin subunits (Scherbaum et al., 2010). 
An arthropod hemocyanin subunit is typically 630-660 amino acids in length, with a molecular mass of $75 \mathrm{kDa}$, and each subunit consists of three domains (Gaykema et al., 1984; Scherbaum et al., 2010). The first N-terminal domain is essentially composed of $\alpha$-helices, and the second domain includes the copper binding sites $\mathrm{CuA}$ and $\mathrm{CuB}$. The third domain mainly consists of $\beta$-sheets, which form the super-secondary structure of a seven-stranded beta-barrel. Oxygen transport is mediated by two copper ions, and either may be bound by three histidines in the CuA sites of the second domain. The first and second domains also include three conserved phenylalanines for oxygen-binding stabilization (Scherbaum et al., 2010).

Despite the identification of hemocyanin subunits in invertebrate animals (Kusche and Burmester, 2001; Kusche et al., 2003; Terwilliger et al., 2006) and the cloning of some homologous sequences (Scherbaum et al., 2010; Sun et al., 2012), some complex problems remain to be resolved. For example, the biological functions of hemocyanin have not been well studied, and the differences and relationships between distinct hemocyanin subunits have not been clearly elucidated. In this study, we attempted to characterize the four full-length Hc cDNAs in S. paramamosain $(\mathrm{SpHc})$, to deduce the corresponding amino acid sequences, and to determine the predicted three-dimensional (3D) structure. Moreover, we aimed to examine the relative expression profiles in different tissues and at various stages. We also assessed the temporal expression patterns of $\mathrm{SpHc}$ mRNA in megalopa after bacterial challenge, hoping to determine the relevance between different $S$. paramamosain hemocyanin subunits.

\section{MATERIAL AND METHODS}

\section{Material and reagents}

Healthy mud crabs $(200 \pm 20 \mathrm{~g})$ were collected from Hainan Island, China. Different organs and tissues, including the hepatopancreas, muscle, gill, testis, heart, and hemocytes were immediately collected and preserved in liquid nitrogen for RNA extraction. Hemocytes were withdrawn with a needle from the unsclerotized membranes of the crab into a syringe containing pre-cooled $\left(-4^{\circ} \mathrm{C}\right)$ anticoagulant $(0.45 \mathrm{M} \mathrm{NaCl}, 0.1 \mathrm{M}$ glucose, $30 \mathrm{mM}$ trisodium citrate, $26 \mathrm{mM}$ citric acid, and $10 \mathrm{mM}$ EDTA, $\mathrm{pH} 4.6)$ to reach a volume ratio of 1:1, and were then pelleted by centrifugation (8000 rpm) (AllegraTM 64R Centrifuge, Beckman Coulter, USA) at $4^{\circ} \mathrm{C}$ for $10 \mathrm{~min}$. Samples from crabs in zoeal (Z) stages Z1, Z2, Z3, Z4, and Z5, as well as in the megalopa and juvenile crab I stages, were collected during the cultivation process on Hainan Island.

\section{cDNA library construction}

An S. paramamosain cDNA library was constructed successfully using a SMART ${ }^{\mathrm{TM}}$ CDNA Library Construction Kit (Clontech, Palo Alto, CA, USA), and all EST sequences were subjected to BLAST analyses (Zhang et al., 2011). BLAST analyses of all EST sequences showed that four EST sequences were highly similar to the previously identified Hcs; therefore, these were selected for further cloning of $\mathrm{SpHc}$ cDNA.

\section{Total RNA extraction and first strand cDNA synthesis}

Total RNA was isolated from hepatopancreas tissue using Unizol Reagents (Biostar, Shanghai, China) following the manufacturer protocol, and was then stored at $-80^{\circ} \mathrm{C}$. The quality 
and concentration were checked by agarose gel electrophoresis and spectrophotometry (DU 800, Beckman Coulter).

First-strand cDNA synthesis was performed using M-MLV reverse transcriptase (Promega Corporation, Madison, WI, USA.) to transcribe poly(A) mRNA with Oligo-dT and random 6-mer primers. Manufacturer recommended reaction conditions were used.

\section{3' RACE and 5' RACE}

The missing 5' and 3' ends of S. paramamosain Hc cDNA were obtained using the rapid amplification of cDNA ends (RACE) method, which was performed using the SMART ${ }^{\mathrm{TM}}$ RACE cDNA Amplification Kit (Clontech) according to the manufacturer instructions. Primers for 5 ' and 3'RACE are provided in Table 1.

Table 1. Primers used to sequence hemocyanin cDNA from Scylla paramamosain (SpHc).

\begin{tabular}{ll}
\hline Primer Name & Sequence $\left(5^{\prime}-3^{\prime}\right)$ \\
\hline SpHc1-3GSP & GTTCTCGCTCTTCAACACCCGCC \\
SpHc1-5GSP & ACGCTGCTCTGGGTTGCTCTTGC \\
SpHc2-3GSP & TACCTTCAACCATTACGGCTGCTAC \\
SpHc2-5GSP & CAATAGCGTTCCAGCGTCCCTCGT \\
SpHc3-3GSP & GCTGACGAGGCTGTGGAGAATAATC \\
SpHc3-5GSP & ATCGTCGGCGGTGTAAGGTGG \\
SpHc4-3GSP & AGGAACTCATCCGCTTGGCTG \\
SpHc4-5GSP & AAGATCGGCGGCGTGTAAGGGG \\
18SRNA-RT-F & GGGGTTTGCAATTGTCTCCC \\
18SRNA-RT-R & GGTGTGTACAAAGGGCAGGG \\
SpHc1-RT-F & CTGATCGAGAAGGCTGAAGAGGCAC \\
SpHc1-RT-R & TGTTGGGTAACCCGAGGCTGCTAT \\
SpHc2-RT-F & CAACCATTACGGCTGCTACGAT \\
SpHc2-RT-R & CTTGAAGTTGAGACGCCAGTGA \\
SpHc3-RT-F & ACTCCAGTGTGACCATCCAAGACCG \\
SpHc3-RT-R & GGATGACCACAGGACCTGCCACTAT \\
SpHc4-RT-F & GGCTATTGCGGTATTCATGGTGG \\
SpHc4-RT-R & GTATGGGAGTGAAGTTGGTTG \\
\hline
\end{tabular}

\section{Sequence analysis}

Identity searches for nucleotide and protein sequences were performed using the BLAST algorithm at NCBI (http://www.ncbi.nlm.nih.gov/). The deduced amino acid sequence was analyzed with the Expert Protein Analysis System (http://www.expasy.org/). Amino acid sequences from various species were retrieved from NCBI GenBank, and were then analyzed using the Vector NTI Suite 11.0, Clustal W Multiple Alignment program (http://www.ebi.ac.uk/clustalw/). A neighborjoining (NJ) phylogenetic tree was constructed using MEGA software version 4.1 (Tamura et al., 2011), and the confidence level in the generated tree was obtained using 1000 bootstraps. The secondary structure of $\mathrm{SpHc}$ was predicted by the application of a hierarchical neural network (http://www.expasy.org/). The 3D structure of SpHc was simulated using the SWISS-MODEL longdistance server (http://www.expasy.org/).

\section{qRT-PCR analysis of SpHc in different tissues and at various stages}

Total RNA was isolated from different tissues and at various developmental stages of 
S. paramamosain using the TRIzol reagent (TaKaRa, Shiga, Japan), which was stored at $-80^{\circ} \mathrm{C}$. Total RNA $(1 \mu \mathrm{g})$ was reverse transcribed with the ReverTra Ace qPCR RT Kit (Toyobo, Osaka, Japan) for first strand cDNA. The products were diluted $(1: 10)$ and stored at $-20^{\circ} \mathrm{C}$ until qRT-PCR analyses were conducted. The SYBR Green qRT-PCR assay using Power SYBR Green PCR master mix (Applied Biosystems, Foster City, CA, USA) was conducted in an ABI Step One Plus Detection system (Applied Biosystems). Amplifications were performed in a 96-well plate with a $20 \mu \mathrm{L}$ reaction volume containing $10 \mu \mathrm{L}$ SYBR Premix Taq TM, $0.8 \mu \mathrm{L}$ PCR Forward Primer (10 $\mathrm{mM}), 0.8 \mu \mathrm{L}$ PCR Reverse Primer (10 mM), 0.4 $\mu \mathrm{L}$ ROX Reference Dyel, $2.0 \mu \mathrm{L}$ cDNA template, and $6.0 \mu \mathrm{L}$ diethylpyrocarbonate water (DEPC-water). The thermal profile for SYBR Green qRTPCR was $30 \mathrm{~s}$ at $95^{\circ} \mathrm{C}$, followed by 40 cycles of $95^{\circ} \mathrm{C}$ for $5 \mathrm{~s}$ and $60^{\circ} \mathrm{C}$ for $34 \mathrm{~s}$. DEPC-water was used to replace the template in the negative control. Fluorescence collection was performed after the completion of each cycle.

A preliminary experimental trial showed that the housekeeping gene $18 S$ rRNA exhibited steady expression in this experimental species. Therefore, 18S rRNA was used as the internal gene in all qRT-PCR assays, and the 18s-RT-F and 18s-RT-R primers were designed based on the $18 S$ rRNA gene sequence (GenBank accession No. FJ646616.1). The standard curve and gene expression levels were automatically analyzed by the system, as was the setting of the base line. Melting curve analyses of the amplification products were performed at the end of each PCR reaction to confirm that only one product was amplified and detected. The experimental qRT-PCR results and observations in different tissues were calculated to derive the means and standard deviations. Four pairs of specific SpHc primers, based on each sequence (SpHc1-4), were designed. Primers for qRT-PCR are provided in Table 1.

\section{Temporal expression patterns of SpHc mRNA in megalopa after bacterial chal- lenge}

To determine whether hemocyanin expression was enhanced by microbial challenge, real-time PCR was used to analyze SpHc mRNA expression levels at the megalopa stage after challenge with $V$. parahaemolyticus. The bacterial challenge experiment was performed by adding $2.5 \times 10^{5} \mathrm{cfu} / \mathrm{mL}$ V. parahaemolyticus suspended in physiological saline to plastic tanks. Larvae at the megalopa stage were randomly placed into the two tanks, and five individuals from each tank were collected at $0,3,6,9,12,24,48$, and $72 \mathrm{~h}$. Untreated larvae were used as the control group. Three replicates were employed for each sampling time point. RNA isolation, cDNA synthesis, and qRT-PCR analyses were conducted as described above. The control group was used as the calibrator, and all data were calculated to derive mean and standard deviation values.

\section{RESULTS}

\section{Cloning of SpHc}

Four full-length cDNA sequences of distinct hemocyanin subunits (SpHc1-4) were obtained in this study (GenBank accession No. KM276085-KM276088). SpHc1, SpHc2, SpHc3, and SpHc4 were 2281 bp, 2002 bp, 2184 bp, and 2069 bp and encoded four putative proteins that were $676,570,672$, and 671 amino acids long, respectively. The theoretical isoelectric point $(p /)$ and 
predicted molecular weight were 5.33/76.8 kDa (SpHc1), 5.31/65.0 kDa (SpHc2), 5.70/76.3 kDa $(\mathrm{SpHc} 3)$, and 5.62/76.4 kDa ( $\mathrm{SpHc} 4)$. All sequences harbored poly-A tails between 11 and $16 \mathrm{bp}$. With the exception of $\mathrm{SpHc4}$, consensus polyadenylation signals (AATAAA) were present between 12 and 20 bp upstream of the poly-A tails.

\section{Sequence analysis}

Conserved sequences and characteristic motifs of copper-binding proteins were identified in the deduced $\mathrm{SpHc}$ amino acid sequences, including six metal-binding histidine residues, putative signal peptide sequences, and carbohydrate attachment sites. Motif scan results indicated the presence of casein kinase II phosphorylation sites, N-myristoylation sites, protein kinase C phosphorylation sites, arthropod hemocyanins/insect LSPs signature $1 / 2$, hemocyanin- $\mathrm{N}$, hemocyanin- $\mathrm{M}$, hemocyanin- $\mathrm{C}$, and the common central domain of tyrosinase in the deduced amino acid sequences of the four subunits. In addition, $\mathrm{SpHc1}$ had a unique protein prenyltransferase alpha subunit repeat profile (PFTA), which was not found in the other subunits. Similarly, SpHc3 had CAMP- and CGMP-dependent protein kinase phosphorylation sites (cAMP-phosphorylation site), a histidine-rich region, and a chlamydia polymorphic membrane protein (Chlam-PMP), and SpHc4 had a unique $\mathrm{N}$-glycosylation site.

According to BLASTP searches of the non-redundant protein database at GenBank (http://blast.ncbi.nlm.nih.gov/Blast.cgi), the deduced amino-acid sequences of SpHc1 and $\mathrm{SpHc} 2$ shared the highest identity (86.0 and $88.0 \%$, respectively) with the hemocyanin subunit of Callinectes sapidus (accession No. AAF64305.1), while SpHc3 shared 80.0\% similarity with the hemocyanin subunit 1 of Metacarcinus magister (accession No. AAW57889.1). $\mathrm{SpHc} 4$ shared $78.0 \%$ similarity with the hemocyanin subunit 2 of $M$. magister (accession No. AAW57890.1). Amino acid sequence alignment was conducted between Hcs reported from other organisms using Vector NTI Suite Advance 11.5, and the results indicated that some amino acid residues were highly conserved in different species (Figure 1). Additionally, using MEGA 4.1, a NJ phylogenetic tree was generated using the complete hemocyanin protein sequences deposited in NCBI (Figure 2). Phylogenetic analyses indicated that SpHc was more similar to homologous genes in crustaceans such as $C$. sapidus and $M$. magister. This result was consistent with current evolutionary results, indicating that the hemocyanin gene could be a molecular index for systematic evolution.

\section{Protein structure of $\mathrm{SpHc}$}

The hierarchical neural network provided a structural model of $\mathrm{SpHc}$. The results showed that the four distinct subunits (SpHc1-4) included 29.4, 23.2, 32.9, and 31.7\% alpha helices, 17.6, 23.0, 15.0, and $16.6 \%$ extended strands, and 53.0, 53.9, 52.1, and 51.7\% random coils, respectively. In addition, the random coil was the major component. SpHc was submitted to the SWISSMODEL server, and Protein Data Bank (PDB) database queries (SpHc1-4) with this program obtained a structure with $60.3,61.0,56.4$, and $54.5 \%$ identity to Panulirus interruptus hemocyanin (PDB accession No. 1hcyC), respectively. Although there was some difference in the hemocyanin protein sequence, the spatial structure was highly conserved in various species (Figure $3 a, b, c$, and $\mathrm{d}$ ). 


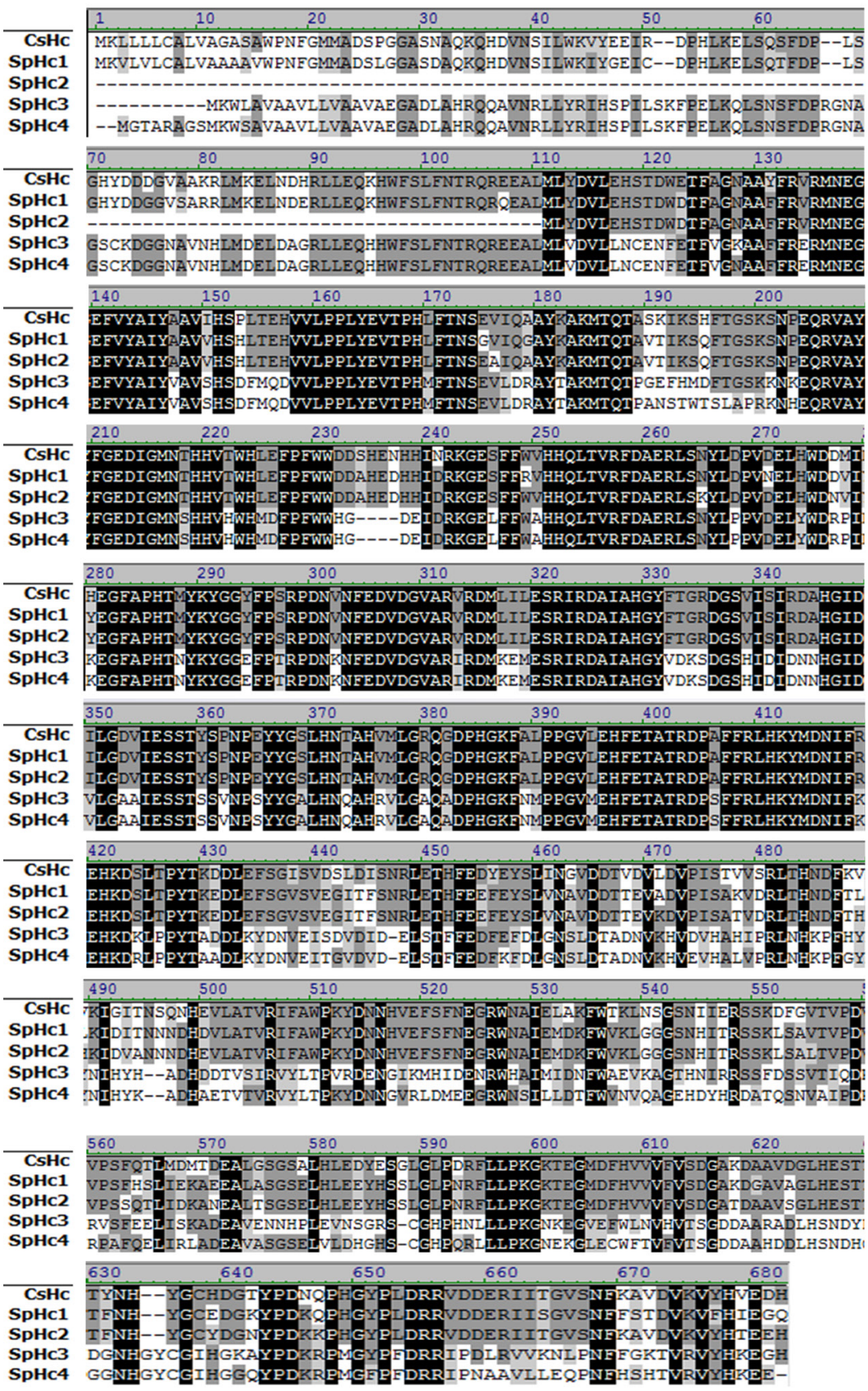

Figure 1. Multiple alignments of the amino acid sequence of selected hemocyanin subunits. Gaps (-) were introduced to maximize the alignment. The relationships between residues are indicated as follows: dissimilar residues, black letters on a white background; conserved residues, black letters on a dark gray background; block of similarity, black letters on a light grey background; identical residues, white letters on a black background. SpHc1-4, Scylla paramamosain hemocyanins 1-4; CsHc, Callinectes sapidus hemocyanin (GenBank accession No. AAF64305.1). 


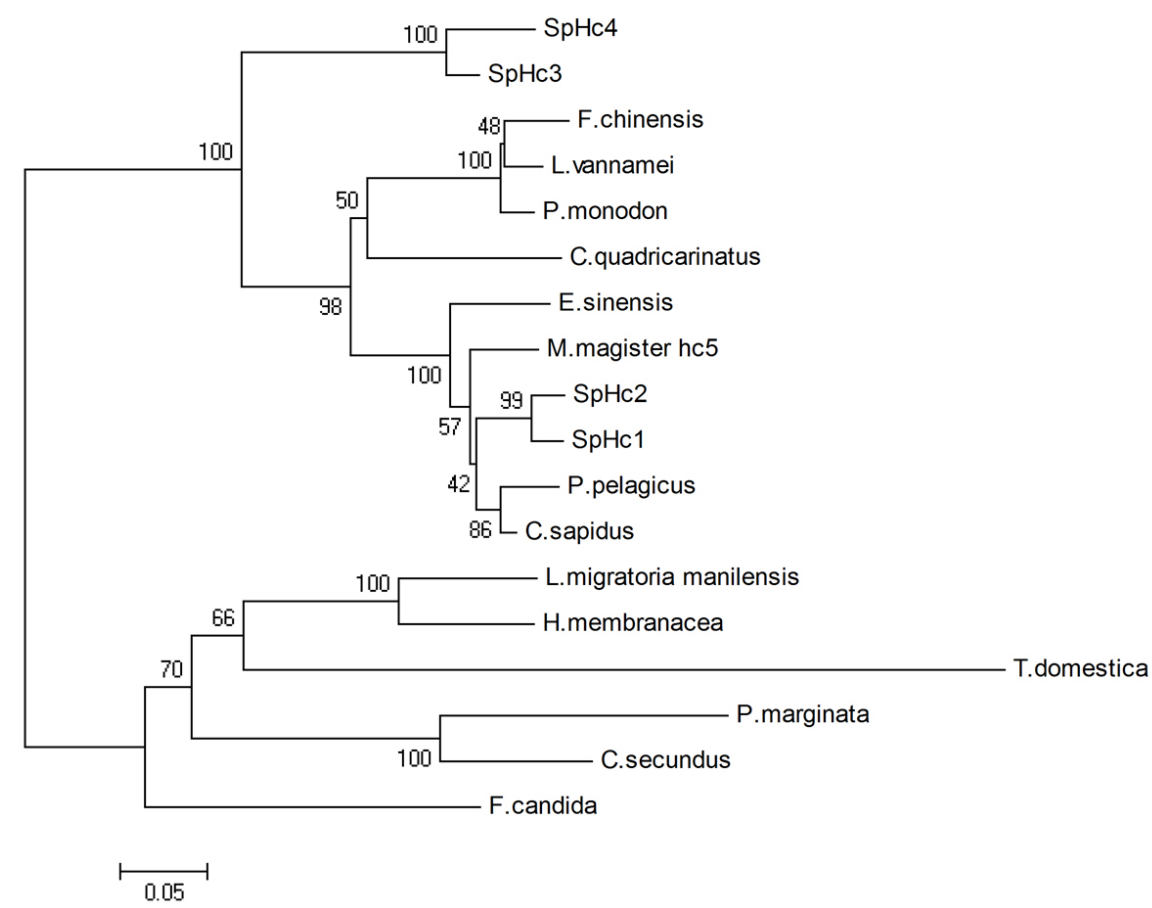

Figure 2. Phylogenetic tree of hemocyanin $(\mathrm{Hc})$. The tree was constructed using the neighbor-joining algorithm in the MEGA 4.1 program based on a multiple sequence alignment by Clustal W, and the reliability of the branching was tested using bootstrap resampling (1000 pseudo-replicates). The scale bar corresponds to the estimated amino acid substitutions per site. The GenBank accession No of the sequences used are as follows: Metacarcinus magister hemocyanin subunits 5 (M. magister hc5: AAW57893.1), Eriocheir sinensis hemocyanin (E. sinensis: AEG64817.1), Cherax quadricarinatus hemocyanin (C. quadricarinatus: AFP23115.1), Litopenaeus vannamei hemocyanin (L. vannamei: AHY86472.1), Penaeus monodon hemocyanin (P. monodon: AEB77775.1), Portunus pelagicus hemocyanin (P. pelagicus ABM74407.1), Hierodula membranacea hemocyanin (H. membranacea: CAR85695.1), Thermobia domestica hemocyanin (T. domestica: CAQ63323.1), Fenneropenaeus chinensis hemocyanin (F. chinensis: ACM61982.1), Locusta migratoria manilensis hemocyanin (L. migratoria manilensis: ADR82619.1), Folsomia candida hemocyanin (F. candida: AHI62557.1), Cryptotermes secundus hemocyanin (C. secundus: CAR85698.1), Perla marginata hemocyanin (P. marginata: CAD87763.1), and Callinectes sapidus hemocyanin (C. sapidus: AAF64305.1).

\section{qRT-PCR analysis of SpHc in different tissues and at various stages}

The qRT-PCR investigation was conducted to identify the spatial and temporal expression of $\mathrm{SpHc}$ in different tissues and during various stages (Figure 4A and 4B). It was obvious that $\mathrm{SpHc}$ was widely distributed in different tissues and stages regardless of the subunit, and the highest expression levels were observed in the hepatopancreas, followed by hemocytes and testis. Marginal levels were observed in the heart, muscle, and gill. However, the results indicate that the expression levels of different hemocyanin subunits at different stages were dissimilar. The lowest levels appeared at the Z1 and Z2 stages regardless of the subunit. SpHc1 and SpHc2 showed low expression levels at the first five stages, rose to higher levels at the megalopa stage, and finally reached the highest expression levels at the juvenile stage. SpHc3 and SpHc4 showed the highest expression levels at the megalopa stage, and then abruptly declined at the juvenile stage. 


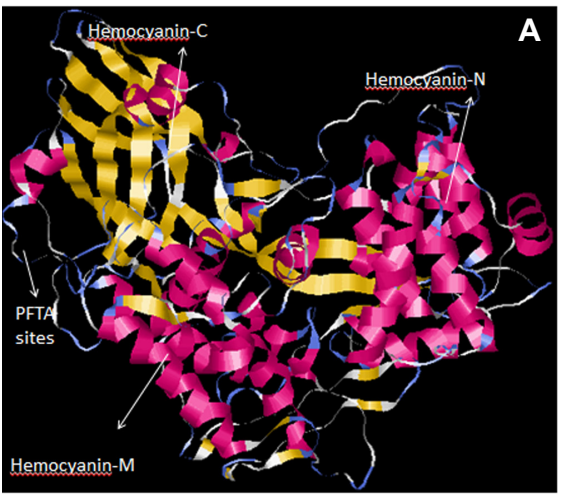

$\mathrm{SpHc1}$

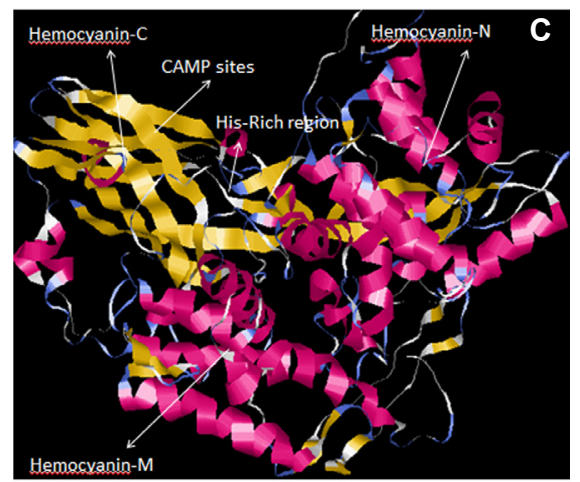

$\mathrm{SpHc3}$

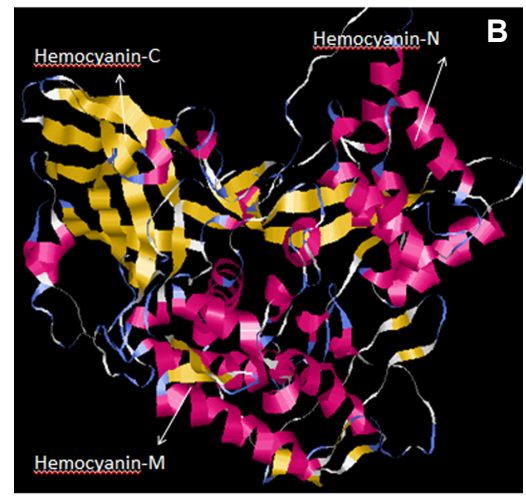

$\mathrm{SpHc} 2$

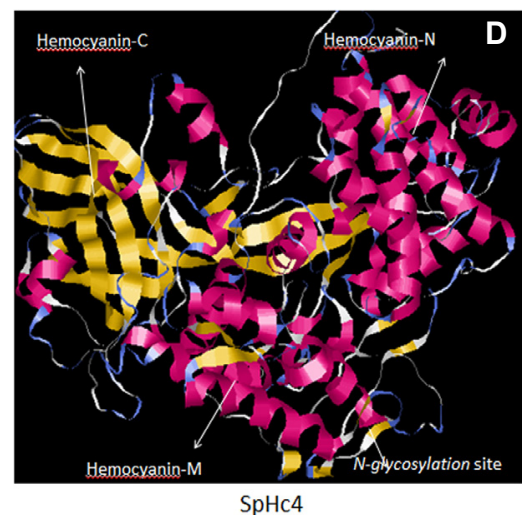

Figure 3. Predicted 3D models. (A) Scylla paramamosain hemocyanin 1 (SpHc1), (B) SpHc2, (C) SpHc3, and (D) $\mathrm{SpHc4}$. The three conserved domains of hemocyanin-N, hemocyanin-M, and hemocyanin-C, from $5^{\prime}$ to 3 ' ends, are shown with arrows. The 3D structures were established based on the SWISS-MODEL.
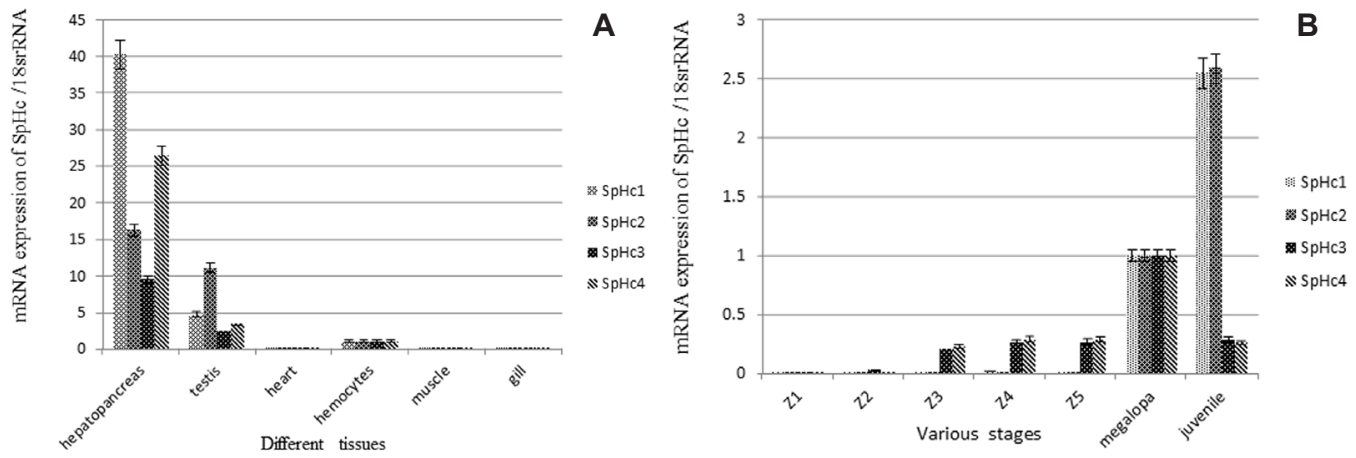

Figure 4. Relative expression levels of SpHc. Expression levels in different tissues (A) and at various developmental stages (B) as detected by quantitative real-time PCR. The amount of Hc mRNA was normalized based on the 18S rRNA transcript level. Data are reported as means \pm SD of the three repeated experiments. The " $Y$ " axis represents the relative ratio of SpHc/18S rRNA mRNA expression levels. SpHc1-4 represents Scylla paramamosain hemocyanin subunits 1-4, and Z1-Z5 represent zoeal stages I-V. The relative ratio in hemocytes at the megalopa stage was initiated as "1.0". 


\section{Temporal expression of SpHc mRNA in the megalopa stage after bacterial challenge}

The time-course expression of $\mathrm{SpHc}$ in the control and challenge groups are shown in Figure 5A and 5B. As shown in Figure 5B, the expression of the four SpHc genes was related to the bacterial challenge as compared to the control group. SpHc mRNA expression declined rapidly during the first $3 \mathrm{~h}$, increased during the next $9 \mathrm{~h}$, peaked at $12 \mathrm{~h}$ after the challenge, and then abruptly declined during the next $12 \mathrm{~h}$. The upregulated expression levels of $\mathrm{SpHc}$ were observed at $48 \mathrm{~h}$ after the challenge, and were then gradually downregulated to the baseline.
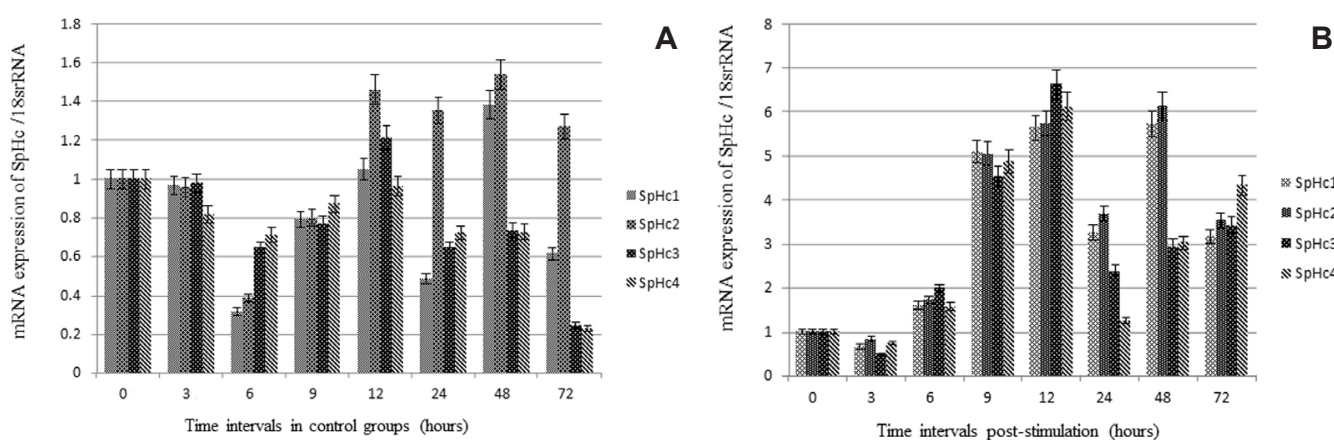

Figure 5. Temporal expression of SpHc mRNA at the megalopa stage at different time intervals in the Vibrio parahaemolyticus challenge. Time-course expression of $\mathrm{SpHc}$ in the control group (A). Time-course expression of $\mathrm{SpHc}$ in the Vibrio parahaemolyticus challenged group (B). The "Y" axis represents the relative ratio of Hc/18S rRNA mRNA expression levels. SpHc1-4 represents Scylla paramamosain hemocyanin subunits 1-4. The relative ratio at the time of "0 h" was initiated as "1.0".

\section{DISCUSSION}

Hemocyanin transports oxygen in the hemolymph of many mollusks and arthropods, and is therefore a central physiological factor in these animals. Studies showed that the evolution of crustacean hemocyanins is strikingly complex, with multiple gene duplications and frequent losses of hemocyanin subunits (Burmester, 2002; Hagner-Holler et al., 2005). As a multifunctional and multi-subunit molecule, the hemocyanin superfamily consists of a large group of proteins that display vast molecular variances (Burmester, 2001; Decker et al., 2007). However, few complete sequences from the Crustacea have been cloned, and no hemocyanin from S. paramamosain has been studied in detail.

In this study, four full-length $S$. paramamosain cDNA sequences were cloned. The results indicated that each of the four subunits consisted of three conserved domains from the $5^{\prime}$ to the $3^{\prime}$ end, known as hemocyanin- $\mathrm{N}$, hemocyanin-M, and hemocyanin-C. This is consistent with the structure of hemocyanin from other arthropods (Gaykema et al., 1984; Sun et al., 2010). During the analysis of $\mathrm{SpHc}$, we found that all four subunits have some similar functional sites or domains, including casein kinase II phosphorylation sites, N-myristoylation sites, protein kinase C phosphorylation sites, arthropod hemocyanins/insect LSPs signature 1/2, hemocyanin- $\mathrm{N}$, hemocyanin-M, hemocyanin-C, and a common central tyrosinase domain. Moreover, with the exception of SpHc2, each gene product had unique functional sites or domains. For instance, SpHc1 had a PFTA that was not found in the other subunits, and $\mathrm{SpHc} 3$ had a cAMP-phosphorylation site, a histidine-rich region, and Chlam-PMP. SpHc4 had an N-glycosylation site and a YLP motif. These findings suggest that the four $S$. paramamosain hemocyanin subunits possibly have different functions. 
Five types of monomeric arthropod hemocyanin subunits have been isolated from Portunus trituberculatus (Fujieda et al., 2010). In addition, five hemocyanin subunits were isolated from Scylla serrata by affinity chromatography, and they were found to have agglutination activities against pathogenic bacteria (Yan et al., 2011). The results of previous studies showed that, apart from its primary function as a respiratory protein for many arthropods, hemocyanin could be functionally converted into a phenoloxidase-like enzyme by different substances, which would allow it to act as an antiviral agent against various viruses or to generate reactive oxygen species (ROS) as an antimicrobial strategy (Decker et al., 2001; Nagai et al., 2001; Zhang et al., 2004; Jiang et al., 2007). S. serrata hemocyanin had agglutination activities against pathogenic bacteria, and the 76-kDa hemocyanin subunit was enough to mediate agglutination (Yan et al., 2011). In this study, four hemocyanin subunits were obtained from S. paramamosain. We inferred that the four distinct $S$. paramamosain hemocyanin subunits might have different functions as is seen throughout Crustacea. However, additional studies are required to better understand the structure and evolution of hemocyanin diversity.

The mRNA expression level is a substantial element affecting the synthesis of hemocyanin. In this study, the results indicated that the expression levels of hemocyanin were dissimilar in different tissues and at various stages. SpHc mRNA expression was detected in all tissues, including the hepatopancreas, gill, muscle, hemocytes, heart, and testis. On one hand, it is very likely that the wide distributions of $\mathrm{SpHc}$ in various tissues result from the infiltration of hemocytes into different tissues, and the results of this study are similar to previous studies on Penaeus japonicus, Fenneropenaeus chinensis, and Eriocheir sinensis (Lei et al., 2008; Sun et al., 2010; Sun et al., 2012). On the other hand, regarding the ubiquitous expression of $\mathrm{SpHc}$ in the testis and muscle, a previous study suggested that hemocyanin might be involved in various biological processes, including non-self innate immunity (Kong et al., 2008). Furthermore, the high expression of SpHc mRNA in the hepatopancreas and hemocytes is consistent with a previous study, which reported that the hepatopancreas is the principal site of hemocyanin synthesis and that hemocytes are a major storage site for hemocyanin in decapod crustaceans (Rainer and Brouwer, 1993). The hepatopancreas and hemocytes are known to be two important tissues in immune defense (Söderhäll and Cereniu, 1998; Gross et al., 2001). This experiment showed that the expression levels of $\mathrm{SpHc1}$ and $\mathrm{SpHc} 2$ were the most abundant in the hepatopancreas and the testis, respectively. These findings suggest the presence of a regulatory mechanism that affects the synthesis of different hemocyanin subunits.

In some crustacean species, distinct hemocyanin subunits may only be present during certain developmental stages, or their synthesis is in response to certain physiological conditions (Markl and Decker, 1992; Durstewitz and Terwilliger, 1997). In this study, SpHc genes were found at various developmental stages. During the first six stages, $\mathrm{SpHc} 3$ and $\mathrm{SpHc} 4$ expression levels were higher than that of $\mathrm{SpHc1}$ and $\mathrm{SpHc2}$, and they declined suddenly during the juvenile stage. During the juvenile stage, SpHc1 and SpHc2 expression levels were the highest, suggesting that $\mathrm{SpHc1}$ and $\mathrm{SpHc2}$ might play a key role at this stage. Above all, the results suggest that $\mathrm{SpHc}$ might play an important role in the molting process, but it may also act in different patterns throughout the course.

Many researchers have reported that the expression levels of hemocyanin genes varied greatly after bacteria or viral challenge. For instance, the expression of EsHc mRNA in E. sinensis increased markedly at $1.5 \mathrm{~h}$ after injection, peaked at $3 \mathrm{~h}$, and then declined to the baseline level at 12 and $24 \mathrm{~h}$ after Aeromonas hydrophila challenge. In addition, two recombinant anionic AMPs were designed to mimic the C-terminus of shrimp Hc, and both AMPs showed broad fungicidal and bactericidal properties (Qiu et al., 2014). We chose the megalopa stage as the subject of investigation because it is the most important stage in the course of crab cultivation. Time-dependent 
patterns of different hemocyanin subunit expression were observed after $V$. parahaemolyticus challenge. In this study, SpHc mRNA expression declined rapidly during the first $3 \mathrm{~h}$, increased during the next $9 \mathrm{~h}$, peaked at $12 \mathrm{~h}$ after challenge, and then abruptly declined during the next $12 \mathrm{~h}$. The observed $\mathrm{SpHc}$ expression levels were upregulated at $48 \mathrm{~h}$ after challenge, and were then gradually downregulated. The expression levels appeared to rise again after $24 \mathrm{~h}$, implying that the $\mathrm{SpHc}$ expression levels could be affected by $V$. parahaemolyticus during the megalopa stage. This result also suggests that hemocyanin may be potentially involved in the immune responses of the mud crab.

The above analyses indicate that different S. paramamosain hemocyanin subunits have distinct expression patterns in various tissues and during different stages. In addition, $\mathrm{SpHc}$ is potentially involved in the immune response of the mud crab. These findings suggest that $S$. paramamosain hemocyanin plays an important antiviral role in the innate immune defense system, and that the role of the four subunits may differ. Further investigations should focus on the mechanisms underlying the regulatory role of hemocyanin in the immune system.

\section{Conflicts of interest}

The authors declare no conflict of interest.

\section{ACKNOWLEDGMENTS}

Research supported by the National Natural Science Foundation of China (\#31101890, \#31310103032), the Science and Technology Commission of Shanghai Municipality (\#10JC1418600), and the Basic Research Fund for State-level Nonprofit Research Institutes of ESCFRI, CAFS (\#2014Z01-2, \#2012T05).

\section{REFERENCES}

Burmester T (2001). Molecular evolution of the arthropod hemocyanin superfamily. Mol. Biol. Evol. 18: 184-195.

Burmester T (2002). Origin and evolution of arthropod hemocyanins and related proteins. J. Comp. Physiol. B 172: 95-107.

Burmester T and Schellen K (1996). Common origin of arthropod tyrosinase, arthropod hemocyanin, insect hexamerin, and dipteran arylphorin receptor. J. Mol. Evol. 42: 713-728.

Decker H and Rimke T (1998). Tarantula hemocyanin shows phenoloxidase activity. J. Biol. Chem. 273: $25889-25892$.

Decker H and Terwilliger N (2000). Cops and robbers: putative evolution of copper oxygen-binding proteins. J. Exper. Biol. 23: 1777-1782.

Decker $\mathrm{H}$ and Jaenicke E (2004). Recent findings on phenoloxidase activity and antimicrobial activity of hemocyanins. Dev. Comp. Immunol. 28: 673-687.

Decker H, Ryan M, Jaenicke E and Terwilliger N (2001). SDS-induced phenoloxidase activity of hemocyanins from Limulus polyphemus, Eurypelma californicum, and Cancer magister. J. Biol. Chem. 276: 17796-17799.

Decker H, Hellmann N, Jaenicke E and Lieb B (2007). Minireview: recent progress in hemocyanin research. Integr. Comp. Biol. 47: 631-644.

Durstewitz G and Terwilliger NB (1997). Developmental changes in hemocyanin expression in the Dungeness crab, Cancer magister. J. Biol. Chem. 272: 4347-4350.

Fujieda N, Yakiyama A and Itoh S (2010). Five monomeric hemocyanin subunits from Portunus trituberculatus: purification, spectroscopic characterization, and quantitative evaluation of phenol monooxygenase activity. BBA-Proteins Proteom. 1804: 2128-2135.

Gaykema WPJ, Hol WGJ, Vereijken JM and Soeter NM (1984). Structure of the copper-containing, oxygen-carrying protein Panulirus interruptus haemocyanin. Nature 309: 23-29.

Gillespie PJ and Kanost MR (1997). Biological mediators of insect immunity. Ann. Rev. Entomol. 42: 611-643.

Gross PS, Bartlett TC, Browdy CL and Chapman RW (2001). Immune gene discovery by expressed sequence tag analysis of hemocytes and hepatopancreas in the Pacific white shrimp, Litopenaeus vannamei, and the Atlantic white shrimp, $L$. setiferus. Dev. Comp. Immunol. 25: 565-577. 
Hagner-Holler S, Kusche K, Hembach A and Burmester T (2005). Biochemical and molecular characterisation of hemocyanin from the amphipod Gammarus roeseli: complex pattern of hemocyanin subunit evolution in Crustacea. J. Comp. Physiol. B 175: 445-452.

Imai H and Takeda M (2005). A natural hybrid mud crab (Decapoda, Portunidae) from Japan. J. Crustacean Biol. 25: 620-624.

Imjongjirak C, Amparyup P, Tassanakajon A and Sittipraneed S (2007). Antilipopolysaccharide factor (ALF) of mud crab Scylla paramamosain: molecular cloning, genomic organization and the antimicrobial activity of its synthetic LPS binding domain. Mol. Immunol. 44: 3195-3203.

Jiang N, Tan NS, Ho B and Ding JL (2007). Respiratory protein-generated reactive oxygen species as an antimicrobial strategy. Nature Immunol. 8: 1114-1122

Kong HJ, Park EM, Nam BH and Kim YO (2008). A C-type lectin like-domain (CTLD)-containing protein (PtLP) from the swimming crab Portunus trituberculatus. Fish Shellfish Immunol. 25: 311-314.

Kusche K and Burmester T (2001). Molecular cloning and evolution of lobster hemocyanin. Biochem. Biophys. Res. Commun. 282: 887-892.

Kusche K, Hembach A, Milke C and Burmester T (2003). Molecular characterisation and evolution of the hemocyanin from the European spiny lobster, Palinurus elephas. J. Comp. Physiol. B 173: 319-325.

Lee SY and Söderhäll K (2002). Early events in crustacean innate immunity. Fish Shellfish Immunol. 12: $421-437$.

Lee SY, Lee BL and Söderhäll K (2004). Processing of crayfish hemocyanin subunits into phenoloxidase. Biochem. Biophys. Res. Commun. 322: 490-496.

Lei KY, Li F, Zhang MC and Yang HJ (2008). Difference between hemocyanin subunits from shrimp Penaeus japonicus in antiWSSV defense. Dev. Comp. Immunol. 32: 808-813.

Markl J and Decker H (1992). Molecular structure of the arthropod hemocyanins. Comp. Environ. Physiol. 13: 325-376.

Nagai T, Osaki T and Kawabata S (2001). Functional conversion of hemocyanin to phenoloxidase by horseshoe crab antimicrobial peptides. J. Biol. Chem. 276: 27166-27170.

Qiu CW, Sun J, Liu M and Wang BJ (2014). Molecular cloning of hemocyanin cDNA from Fenneropenaeus chinensis and antimicrobial analysis of two C-terminal fragments. Marine Biotechnol. 16: 46-93.

Rainer J and Brouwer M (1993). Hemocyanin synthesis in the blue crab Callinectes sapidus. Comp. Biochem. Physiol. B: Comp. Biochem. 104: 69-73.

Söderhäll K and Cereniu L (1998). Role of the prophenoloxidase-activating system in invertebrate immunity. Curr. Opin. Immunol. 10: 23-28.

Sakazaki R, Iwanami S and Fukumi H (1963). Studies on the enteropathogenic, facultatively halophilic bacteria, Vibrio parahaemolyticus. I. Morphological, cultural and biochemical properties and its taxonomical position. Jpn. J. Med. Sci. Biol. 16: 161-188.

Scherbaum S, Ertas B, Gebauer W and Burmester T (2010). Characterization of hemocyanin from the peacock mantis shrimp Odontodactylus scyllarus (Malacostraca: Hoplocarida). J. Comp. Physiol. B 180: 1235.

Sritunyalucksana K and Söderhäll K (2000). The proPO and clotting system in crustaceans. Aquaculture 191: 53-69.

Sun J, Wang BJ, Sun SJ and Li XH (2010). cDNA cloning and sequence analysis of hemocyanin in Fenneropenaeus chinensis. Progr. Fish. Sci. 31: 80-88.

Sun SM, Chen LQ, Qin JG and Ye JY (2012). Molecular cloning, characterization and mRNA expression of copper-binding protein hemocyanin subunit in Chinese mitten crab, Eriocheir sinensis. Fish Shellfish Immunol. 33: 1222-1228.

Tamura K, Peterson D and Peterson N (2011). MEGA5: molecular evolutionary genetics analysis using maximum likelihood, evolutionary distance, and maximum parsimony methods. Mol. Biol. Evol. 28: 2731-2739.

Terwilliger NB, Ryan M and Phillips MR (2006). Crustacean hemocyanin gene family and microarray studies of expression change during eco-physiological stress. Integr. Comp. Biol. 46: 991-999.

Yan F, Zhang YL, Jiang R and Zhong M (2011). Identification and agglutination properties of hemocyanin from the mud crab (Scylla serrata). Fish Shellfish Immunol. 30: 354-360.

Zhang D, Jiang KJ and Zhang FY (2011). Isolation and characterization of a ferritin cDNA from the mud crab Scylla paramamosain. J. Crust. Biol. 31: 345-351.

Zhang FY, Jiang KJ, Sun MM and Zhang D (2013). Multiplex immune-related genes expression analysis response to bacterial challenge in mud crab, Scylla paramamosain. Fish Shellfish Immunol. 34: 712-716.

Zhang X, Huang C and Qin Q (2004). Antiviral properties of hemocyanin isolated from shrimp Penaeus monodon. Antiviral Res. 61: 93-99. 